Discussion This realist review revealed that effective RPs depend largely on strong intersectoral actions involving leadership shared among healthcare, workplace and insurance stakeholders. These findings confirm the complex nature of program implementation.

\section{LEGAL AND POLICY PROVISIONS FOR REASONABLE ACCOMMODATION IN EMPLOYMENT OF PERSONS WITH MENTAL DISABILITY IN EAST AFRICA: A REVIEW}

${ }^{1}$ ID Ebuenyi*, ${ }^{2} \mathrm{M}$ Nthenge, ${ }^{1} \mathrm{~B}$ Regeer, ${ }^{1} \mathrm{~J}$ Bunders. 'Athena Institute, Faculty of Sciences, Vrije Universiteit Amsterdam, The Netherlands; ${ }^{2}$ Independent Consultant on disability rights, gender and youth issues, Kenya

\subsection{6/oemed-2018-ICOHabstracts.1568}

Introduction Globally, legal and policy provisions recommends reasonable accommodation for persons with disability. These provisions are endorsed by international human rights policy provisions and the country specific disability and mental health legislations. However, persons with mental disability continue to face significant limitations to employment in East Africa. Imprecise definitions of mental disability and reasonable accommodation have been blamed for non-implementation of the policy and legal provisions.

Methods The disability laws, human rights legislations and mental health laws of 18 East African countries were reviewed using the WHO MiNDbank and in relation to article 27 of the United Nations Convention on Rights for persons with disabilities(CRPD).

Results We found that although $14(78 \%)$ of the countries have ratified the CRPD only $12(67 \%)$ have explicit definition of mental illness as a disability. Only 11 (62\%) have explicit laws mandating employers to provide reasonable accommodation for persons with mental disability. It is unclear whether the policy and legal provisions perceive reasonable accommodation as a progressive or immediate obligation of the countries.

Discussion The UN CRPD defines persons with disabilities to include those who have long-term physical, mental, intellectual or sensory impairments, which in interaction with various barriers may hinder their full and effective participation in society on equal basis with others Both the CRPD and Sustainable Development(SDG) Goals recommends inclusive employment for persons with all forms of disabilities. In spite of the availability of these legislations, opportunities of employment for persons with mental disabilities remain dismal on account of cultural and social stereotypes about mental illness in addition to absence of actionable points in policies and legislations. There is lack of clear and specific definition of reasonable accommodation in the examined laws and concerted action by all state parties is required for improved employment for persons with mental disability.

\section{RETROSPECTIVE STUDY OF THE PROFILE OF DISABLED EX-WORKERS APPLYING FOR THE DISABILITY PENSION OF THE BRAZILIAN NATIONAL SOCIAL SECURITY INSTITUTE}

LR Ferreira, VASB Capeli, RL Fregonesi, AFA Lemos, CM Galhardi. UNIFAE Medical School, São João da Boa Vista-SP, Brazil

10.1136/oemed-2018-ICOHabstracts. 1569
Introduction The assessment of the disabled person can be carried out through the application of various instruments, such as the International Classification of Functioning, Disability and Health (ICF). It has been used by INSS since 2011 for the concession of disability pension (DP) benefit. Since its implementation as an evaluation instrument, little is known about the results of ICF application and the applicant`s profile. For this reason, it is important to retrospectively analyse the profile of the individuals that require this benefit, in relation to gender, age, educational level and previous main occupation.

Methods A retrospective study was carried out involving the evaluation of 173 DP applicants from the Brazilian National Social Security Institute (INSS) from March 2016 until December 2016 and it was collected the following data: gender, age, educational level, marital status, International Classification of Diseases (ICD10) and previous main occupation. The data were divided according to the main prevalent categories.

Results It was demonstrated that most applicants were female, single, with complete primary education and average age of 43 years-old, with the most frequent distribution of requests occurred between 55 and 59 years-old, the most of them were agricultural wokers (42\%). In regard to ICD-10 classification, the most common disorders were: psychiatric $(25,52 \%)$ followed by neurological/muscle $(15,90 \%)$, cardiovascular $(10,46 \%)$ and trauma/sequelae $(8,36 \%)$ diseases.

Discussion It was concluded that most applicants for the DP benefits were agricultural female workers with low education presenting mainly with psychiatric, neurological, cardiologic and trauma diseases. The use of the ICF as an instrument can contribute to the real living conditions of people with disabilities being included in the statistics, allowing actions and decisions to be guided, policies and interventions defined and budgets allocated.

\section{EVALUATION OF THE INTERNATIONAL CLASSIFICATION OF FUNCTIONING, DISABILITY AND HEALTH FOR ASSESSING DISABILITY OF THE BRAZILIAN NATIONAL SOCIAL SECURITY INSTITUTE}

LR Ferreira*, VASB Capeli, RL Fregonesi, AFA Lemos, CM Galhardi. UNIFAE Medical School, São João da Boa Vista-SP, Brazil

\subsection{6/oemed-2018-ICOHabstracts. 1570}

Introduction The assessment of the person with disabilities can be made by using the ICF (International Classification of Functioning, Disability and Health). It has been used by the Brazilian National Social Security Institute (INSS) to concede the Social Security Continuous Benefit (BPC) for disabled person, and it evaluates incapacity for work and independent life. This study analysed the results of the ICF used by the social security medical examiners and social workers on the evaluation of disabled person.

Methods This was a retrospective study involving the evaluation of 173 BPC applicants of the INSS in Brazil from March to December 2016 and collected the following data: average scores from 0 to 4 (0-no disability, 1-mild, 2-moderate, 3severe, 4-complete disability) for these ICF domains: environmental factors and activities/participation made by the social worker, body functions and activities/participation made by the medical examiners and the final results for granting or not the benefit. It was applied the statistical test of Kruskal-Wallis, the post test of Dunn $(\mathrm{p}<0.05)$. 
Results The results revealed that $71.1 \%$ of the concessions were denied and $28.9 \%$ were granted. It was showed divergent values between the medical evaluation with lower values (mean scores of 0.4 ) in the activity/participation domain compared with results of higher values obtained from the social assistants (mean scores of 3.0) for the same domain. These results were statistically significant with $\mathrm{p}<0.001$.

Discussion The results were divergent when comparing the evaluations made by the medical examiners and social workers. These results may help assist in a better understanding of the analysis of the ICF as an instrument for the evaluation of BPC. It is suggested the need of possibly better standardisation in the method of the ICF instrument application in order to minimise the divergence of results

\section{HEALTH PROBLEMS IN EARLY ADULTHOOD PREDICT DISABILITY RETIREMENT}

${ }^{1} \mathrm{H}$ Frilander*, ${ }^{1} \mathrm{~T}$ Lallukka, ${ }^{1} \mathrm{E}$ Viikari-Juntura, ${ }^{2} \mathrm{M}$ Heliövaara, ${ }^{1} \mathrm{~S}$ Solovieva. ${ }^{1}$ Finnish Institute of Occupational Health, Helsinki, Finland; ${ }^{2}$ National Institute for Health and Welfare, Helsinki, Finland

\subsection{6/oemed-2018-ICOHabstracts.1571}

Introduction Disability retirement causes a substantial burden on the society and affects the well-being of individuals. Early health problems as determinants of disability retirement have received little attention. The aim was to study, whether interrupting compulsory military service is an early indicator of disability retirement among Finnish men and whether seeking medical advice during military service increases the risk of allcause disability retirement and disability retirement due to mental disorders and musculoskeletal diseases. We also looked at secular trends in these associations.

Methods We examined a nationally representative sample of 2069 men, who had entered their compulsory military service during 1967-1996. We linked military service health records with cause-specific register data on disability retirement from 1968 to 2008. We explored secular trends in three service time strata. Cox regression model were used to estimate proportional hazard ratios and their 95\% confidence intervals.

Result During the follow-up time 140 (6.8\%) men retired due to disability, mental disorders being the most common cause. The men who interrupted service had a remarkably higher cumulative incidence of disability retirement (18.9\%). The associations between seeking medical advice during military service and all-cause disability retirement were similar across the three service time cohorts (overall hazard ratio 1.40 per one standard deviation of the number of visits; $95 \%$ confidence interval 1.26-1.56). Visits due to mental problems predicted disability retirement due to mental disorders in the men who served between 1987 and 1996 and a tendency for a similar cause-specific association was seen for musculoskeletal diseases in the men who served in 1967-1976.

Discussion Health problems, in particular mental problems, during late adolescence are strong determinants of disability retirement. Conscription examinations and military service provide access to the entire age cohort of men, where persons at risk for work disability can be identified and early preventive measures initiated.

\section{PEOPLE WITH DISABILITIES: PERCEIVED WORK EXPERIENCE AND HEALTH CONSEQUENCES}

${ }^{1}$ Andréia de Conto Garbin*, ${ }^{2}$ Frida Marina Fischer. ${ }^{1}$ Pontifical Catholic University of São Paulo and Mackenzie Presbyterian University, São Paulo São Paulo, Brazil; ${ }^{2}$ Department of Environmental Health, School of Public Health, University of São Paulo, São Paulo, Brazil

\subsection{6/oemed-2018-ICOHabstracts. 1572}

Introduction Brazilian private and public employers must reserve jobs to hire persons with disabilities. The inclusion operates precariously. Often employees are required to work in low skills jobs following taylorism-fordism or toyotism production modes. This study aimed to investigate perceived job experiences of workers with disabilities and impact on health. Methods This is a qualitative case study carried in São Paulo, Brazil. Focus groups (6) and interviews (4) with people with physical disabilities and deaf were performed. Physical disabilities were acquired in some cases as a result of work injuries, due to unsafe work conditions, and the perversity of the system projecting the worker to a condition of disabled person.

Results It prevails the discourse of disabled workers with unqualified skills. It is sought to include those who depend on few adaptations of the work environment. The requirements for professional qualification are based on the ideology of adjustment'. It becomes effective as inclusion programs aim to discipline behaviours, organisers of social life. These are requirements regarding subjectivity, modes of living, with emphasis on individual persistence and overcoming difficulties. Subtle control operates through the discourse of inclusion and the worker acquires the condition of reification.

Discussion Nowadays the deaf are limited in the use of their main mode of communication, the hands. There is a discourse in the companies about the 'productive deaf' reproducing the cultural isolation of the deaf people. The excluded, disguised as included, experience suffering related to social injustices and psychological violence. Regarding the work injuries, the degradation and precariousness of work generate a subpopulation of persons with disabilities, but denies them access to an effective rehabilitation system. Public policies should prevent the production of a double discrimination. It is also necessary to change the common speech labelling the disabled person as a disqualified professional.

\section{PREDICTING LONG-TERM SICKNESS ABSENCE AND SUPPORTING RETURN-TO WORK PROCESSES USING QUESTIONNAIRES}

${ }^{1} \mathrm{~K}$ Goorts ${ }^{*},{ }^{2,3} \mathrm{D}$ Rusu, ${ }^{1} \mathrm{M}$ Du Bois, ${ }^{1,4} \mathrm{~S}$ Vandenbroeck, ${ }^{4} \mathrm{C}$ Duchesnes, ${ }^{2} \mathrm{PH}$ Mairiaux, ${ }^{5} \mathrm{~S}$ Decuman, ${ }^{1,4} \mathrm{~L}$ Godderis. ${ }^{1}$ Katholieke Universiteit Leuven, Leuven, Belgium; ${ }^{2}$ Université de Liège, Belgium; ${ }^{3}$ SPMT-ARISTA, Brussels, Belgium; ${ }^{4}$ Idewe, Heverlee, Belgium; ${ }^{5}$ RIZIV, Brussels, Belgium

\subsection{6/oemed-2018-ICOHabstracts. 1573}

Introduction Promoting good health and attendance, instead of penalising absence, has become a growing policy issue, since long-term sickness absence is increasing in 27 European member states and Norway. As most employees will return to work spontaneously, resources for return to work projects should be dedicated to the high-risk group for long-term sickness absence. 